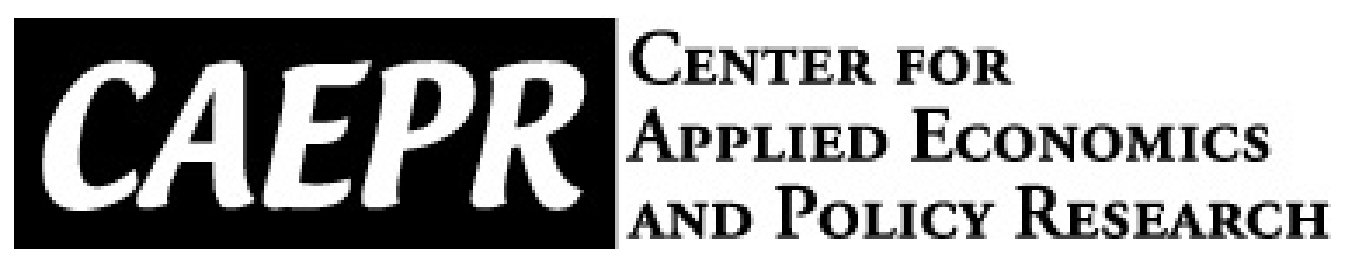

CAEPR Working Paper

\#016-2009

\title{
Exchange Rates, Oil Price Shocks, and Monetary Policy in an Economy with Traded and Non-Traded Goods.
}

\author{
Michael Plante
}

Indiana University

August 14, 2009

This paper can be downloaded without charge from the Social Science Research Network electronic library at: http://ssrn.com/abstract=1456396.

The Center for Applied Economics and Policy Research resides in the Department of Economics at Indiana University Bloomington. CAEPR can be found on the Internet at: http://www.indiana.edu/ caepr. CAEPR can be reached via email at caepr@indiana.edu or via phone at 812-855-4050.

(C2008 by NAME. All rights reserved. Short sections of text, not to exceed two paragraphs, may be quoted without explicit permission provided that full credit, including $\odot$ notice, is given to the source. 


\title{
Exchange Rates, Oil Price Shocks, and Monetary Policy in an Economy with Traded and Non-Traded Goods.*
}

\author{
Michael Plante ${ }^{\dagger}$
}

August, 2009

\begin{abstract}
This paper examines monetary policy responses to oil price shocks in a small open economy that produces traded and non-traded goods. When only labor and oil are used in production and prices are sticky in the non-traded sector the behavior of inflation, the nominal exchange rate, and the relative price of the non-traded good depends crucially upon whether the ratio of the cost share of oil to the cost share of labor is higher for the traded or non-traded sector. If the ratio is smaller (higher) for the traded sector then a policy that fully stabilizes non-traded inflation causes the nominal exchange rate to appreciate (depreciate) and the relative price of the non-traded good to rise (fall) when there is a surprise rise in the price of oil. Similar results can hold for a policy that stabilizes CPI inflation. Under a policy that fixes the nominal exchange rate, non-traded inflation rises (falls) if the ratio is smaller (larger) for the traded sector. Analytical results show that a policy of fixing the exchange rate always produces a unique solution and that a policy of stabilizing non-traded inflation produces a unique solution so long as the nominal interest rate is raised more than one-for-one with rises in non-traded inflation. A policy that stabilizes CPI inflation, however, produces multiple equilibria for a wide range of calibrations of the policy rule.
\end{abstract}

Keywords: oil prices, monetary policy, inflation, exchange rates

JEL Classifications: F41, E52, Q43

*Date: August, 2009. Any comments would be greatly appreciated. I would like to thank my advisor Ed Buffie for many helpful comments about this paper. As always, I assume full responsibility for any and all errors.

${ }^{\dagger}$ Department of Economics, Ball State University, Whitinger Business Building, 2000 W. University Ave., Muncie, IN 47304, or by e-mail at mdplante@bsu.edu 


\section{Introduction}

A search of the recent literature turns up a number of papers written on how policy makers should respond to oil price shocks, including but not limited to Leduc and Sill (2004), Dhawan and Jeske (2007), Plante (2009a), and Bodenstein, Erceg, and Guerrieri (2008). With almost no exceptions this work makes use of models suited for a large developed country, such as the United States. For policy makers from small open economies who may be concerned with nominal exchange rates, real exchange rates, and trade balances, there is a dearth of results available. This is true despite the fact that many small open economies are heavy users of oil products and hence are vulnerable to oil price shocks in the same way that large economies are.

In this paper I address this issue by developing a continuous time, small open economy model that can be used to investigate the performance of different specifications of monetary policy when the price of oil changes. The economy is small, fully integrated into world capital markets, and uses labor and oil to produce both traded and non-traded goods. Prices are sticky in the non-traded sector so that monetary policy may have important real effects on the economy. To my knowledge this is the first paper in this area of work that uses a dynamic general equilibrium model that contains traded and non-traded goods.

Using this model I consider the performance of three different specifications of monetary

policy. The first is an inflation targeting policy that stabilizes the inflation rate of prices in the non-traded sector (non-traded inflation). The second policy considered is an inflation targeting policy that stabilizes CPI inflation. The third policy fixes the nominal exchange rate through intervention in the foreign exchange market. I present both analytical and numerical results regarding the behavior of the model's variables under each policy and analytical results which show the conditions under which each policy generates a unique solution.

The main results are the following. First, I show that whether the ratio of the cost share of oil to labor is higher in the traded or non-traded sectors is crucial to pinning down the 
behavior of many of the model's variables. For example, under a policy that successfully stabilizes non-traded inflation around its target level it is possible for the nominal exchange rate to appreciate or depreciate and the relative price of the non-traded good to rise or fall depending upon the ratios. If the ratio is higher in the non-traded sector then a rise in the price of oil causes the nominal exchange rate to appreciate and the relative price of the non-traded good to rise. If the ratio is lower for the non-traded sector then the opposite occurs. For certain calibrations of the monetary policy rule, a similar result holds for the policy that stabilizes CPI inflation. Under a policy of fixed exchange rates, the response of non-traded inflation is pinned down by the ratio and rises (falls) when the ratio is higher (lower) in the non-traded sector.

The intuition behind these results is that the oil price shock may have asymmetric effects on costs (and hence inflation) in the traded and non-traded sectors. A policy of stabilizing non-traded inflation works by offsetting any changes in cost in the non-traded sector by properly adjusting the nominal exchange rate over time. But since costs may rise or fall in the non-traded sector (holding the exchange rate fixed) this policy may bring about nominal exchange rate appreciation or depreciation. Similar intuition explains the results for the fixed exchange rate policy. Under this policy the nominal exchange rate is not used to change costs in the non-traded sector and consequently inflation rises (falls) when costs rise (fall) in the non-traded sector.

I also derive analytical results that show under what conditions these policies produce a unique solution. The results show that a policy that fixes the nominal exchange rate always produces a unique solution while a policy which stabilizes non-traded inflation produces a unique solution so long as the nominal interest rate is raised by more than one-for-one with movements in non-traded inflation. Under a policy that stabilizes CPI inflation, however, multiple equilibria occur for a wide range of calibrations for the policy rule. The analytical results show that the weight of the non-traded good in the CPI is very important in determining what areas of the parameter space produce indeterminacy.

The paper proceeds as follows. Section 2 introduces the details of the model and the solution 
procedure. Section 3 presents the results. Finally, the paper concludes in section 4 .

\section{The Model}

The model is a continuous time, perfect foresight model of a small, open economy. The economy is small in that it is a price-taker with regards to the traded good and oil products. Economic activity on the household side is controlled by a representative agent who derives utility from traded and non-traded consumption goods and dis-utility from providing labor to the traded and non-traded sectors. The agent has access to a domestic currency, a domestic nominal bond, and tradable real bond. Money is motivated by assuming that holdings of real money balances provides utility to the agent. On the production side, the traded and non-traded goods are produced using oil and labor. The traded good is produced by a representative firm operating under perfect competition while the non-traded good is an aggregate of differentiated products produced by a continuum of firms operating under monopolistic competition.

As far as notation is concerned, $d X$ is the differential of the variable $X, \dot{X}$ is the time derivative of $X, X_{o}$ is the steady state value of $X$, and $\hat{X}$ is the log-differential of $X$, i.e. $\hat{X}=\frac{d X}{X}$.

\section{$2.1 \quad$ Prices}

The traded good is the numeraire and sells domestically at a price of $e P^{t}$, where $e$ is the nominal exchange rate and $P^{t}$ is the world price of the traded good in dollars. The nominal exchange rate measures the number of units of domestic currency per 1 dollar and the rate of depreciation is

$$
\chi=\frac{\dot{e}}{e} .
$$

For convenience I assume that $P^{t}$ is constant and equal to 1 so nominal variables are deflated by $e$. In general, nominal variables are denoted with a tilde while their real versions are not. 
The nominal price of the non-traded good is given by $\tilde{P}^{n}$, with an inflation rate of

$$
\pi^{n}=\frac{\dot{\tilde{P}^{n}}}{\tilde{P}^{n}}
$$

The relative price of the non-traded good is denoted as $P^{n}$ and is controlled by the differential equation

$$
\dot{P}^{n}=P^{n}\left(\pi^{n}-\chi\right)
$$

Real wages are denoted as $W^{n}$ and $W^{t}$ for the non-traded and traded sectors, respectively. The dollar price of oil in world markets is denoted as $P^{o}$.

Two official measures of prices are also used here. The first is the Consumer Price Index (CPI), $\tilde{P}^{C P I}$, which in this model is also equivalent to the core CPI as households do not directly purchase oil products. The other is the GDP deflator, $\tilde{P}^{G D P}$. The formulas used to calculate these are given later.

\subsection{The Agent's Optimization Problem}

The agent's instantaneous utility function is of the form

$$
\frac{C^{1-\frac{1}{\tau}}}{1-\frac{1}{\tau}}+\kappa_{2} \frac{\left(\frac{m}{P^{C P I}}\right)^{1-\frac{1}{\tau}}}{1-\frac{1}{\tau}}-\kappa_{3} \frac{\left(L^{n}+L^{t}\right)^{1+\frac{1}{\mu}}}{1+\frac{1}{\mu}}
$$

where

$$
C\left(C^{t}, C^{n}\right)=\left[C^{t \frac{\sigma_{c}-1}{\sigma_{c}}}+\kappa_{1} C^{n \frac{\sigma_{c}-1}{\sigma_{c}}}\right]^{\frac{\sigma_{c}}{\sigma_{c}-1}}
$$

aggregates non-traded consumption goods $C^{n}$ and traded consumption goods $C^{t}$ to produce an aggregate measure of consumption, $C$. The parameters $\tau, \sigma_{c}$, and $\mu$ are the intertemporal elasticity of substitution, the elasticity of substitution between traded and non-traded consumption goods, and the wage elasticity of labor supply, respectively. Total labor supply is $L=L^{n}+L^{t}$ where $L^{t}$ is the amount of labor provided to the traded sector and $L^{n}=\int_{0}^{1} L^{n}(i) d i$ is aggregate labor supplied to firms in the non-traded sector. The term 
$m=\frac{M}{e}$ is real holdings of domestic currency while $P^{C P I}$ is the CPI deflated by the nominal exchange rate.

I simplify the utility function by replacing $C$ with its indirect utility version. This is done by solving for the Marshallian demand functions of $C^{t}$ and $C^{n}$ and substituting them back into $C$, i.e. maximizing $C$ subject to the constraint that $C^{t}+P^{n} C^{n}=E$, where $E$ is real aggregate consumption expenditure. After this is done the term representing utility from consumption is

$$
\frac{\left(\frac{E}{P^{C P I}}\right)^{1-\frac{1}{\tau}}}{1-\frac{1}{\tau}} .
$$

The functional form for the utility function implies that the exact equation for $P^{C P I}$ is

$$
P^{C P I}=\left(1+\kappa_{1}^{\sigma_{c}} P^{n 1-\sigma_{c}}\right)^{\frac{1}{1-\sigma_{c}}}
$$

CPI inflation is therefore

$$
\pi^{C P I}=\chi+\gamma_{n} \frac{\dot{P}^{n}}{P^{n}}
$$

where $\gamma_{n}$ is the share of non-traded consumption out of aggregate consumption spending. Real wealth is given by

$$
A=m+b^{*}+b,
$$

where $b^{*}$ is holdings of the tradable real bond and $b$ is real holdings of a nominal bond traded domestically. The real flow constraint for the agent is given by

$$
\dot{A}=W^{n} L^{n}+W^{t} L^{t}+r^{*} b^{*}+(i-\chi) b+T+\Pi^{n}-E-\chi m .
$$

In the budget constraint $T$ is lump sum transfers from the government, $\Pi^{n}$ is rebated profits from the non-traded sector, $r^{*}$ is the real interest rate paid on the tradable bond, and $i$ is the nominal interest rate paid on the domestic bond. 
The agent's problem is to maximize

$$
\int_{0}^{\infty}\left\{\frac{\left(\frac{E}{P^{C P I}}\right)^{1-\frac{1}{\tau}}}{1-\frac{1}{\tau}}+\kappa_{2} \frac{\left(\frac{m}{P^{C P I}}\right)^{1-\frac{1}{\tau}}}{1-\frac{1}{\tau}}-\kappa_{3} \frac{\left(L^{n}+L^{t}\right)^{1+\frac{1}{\mu}}}{1+\frac{1}{\mu}}\right\} e^{-\rho t} d t
$$

subject to equations (4) and (5). Defining $\lambda_{1}$ as the multiplier on the flow constraint, the first order conditions for the household's problem can be written as

$$
\begin{aligned}
\frac{E^{-\frac{1}{\tau}}}{P C P I^{1-\frac{1}{\tau}}} & =\lambda_{1}, \\
\kappa_{2}\left(\frac{m}{E}\right)^{-\frac{1}{\tau}} & =i, \\
i & =r^{*}+\chi, \\
\kappa_{3} L^{\frac{1}{\mu}} & =\lambda_{1} W^{n}, \\
\kappa_{3} L^{\frac{1}{\mu}} & =\lambda_{1} W^{t}, \\
\frac{\dot{\lambda}_{1}}{\lambda_{1}} & =\rho-r^{*} .
\end{aligned}
$$

The first order conditions for $E$ and $m$ are standard. The first order condition for $b$ provides a no-arbitrage condition that sets the domestic nominal interest rate $i$ equal to the world real interest rate plus the rate of depreciation. Equations $(10)$ and $(11)$ set the foregone utility lost from working more in each sector equal to the respective benefit of working more in that sector. As labor is intersectorally mobile and wages are flexible, combining these equations gives the condition that

$$
W^{t}=W^{n}
$$

Since the two are equal at all times I simply refer to the real wage as $W$. The remaining equation then reads

$$
\kappa_{3} L^{\frac{1}{\mu}}=\lambda_{1} W
$$

This equation pins down the aggregate labor supply decision of the agent as a function of the marginal utility of income and the real wage. Finally, the first order condition for $A$ 
gives the condition that $\dot{\lambda}_{1}=0$ for all $t$ as $\rho=r^{*}$.

\subsection{Production}

Production in the traded sector is done by a representative firm operating under perfect competition. Technology in this sector is

$$
Q^{t}=A^{t}\left[L^{t \frac{\sigma_{t}-1}{\sigma_{t}}}+b_{1} O^{t \frac{\sigma_{t}-1}{\sigma_{t}}}\right]^{\frac{\sigma_{t}}{\sigma_{t}-1}}
$$

where $\sigma_{t}$ is the elasticity of substitution between labor and oil and $b_{1}$ is a distribution parameter. The real unit cost function for this technology is

$$
\phi^{t}=\frac{1}{A^{t}}\left[W^{1-\sigma_{t}}+b_{1}^{\sigma_{t}} P^{o 1-\sigma_{t}}\right]^{\frac{1}{1-\sigma_{t}}} .
$$

The factor demands for labor and oil are given by

$$
L^{t}=A^{t^{\sigma_{t}-1}} W^{-\sigma_{t}} Q^{t}
$$

and

$$
O^{t}=A^{t^{\sigma_{t}-1}} b_{1}^{\sigma_{t}} P^{o-\sigma_{t}} Q^{t}
$$

respectively.

Production in the non-traded sector is done by a continuum of firms operating under monopolistic competition. Each firm produces a differentiated good, $Q^{n}(i)$, which it sells for $\tilde{p}(i)$. Technology for firm $i$ is

$$
Q^{n}(i)=A^{n}\left[L^{n}(i)^{\frac{\sigma_{n}-1}{\sigma_{n}}}+b_{2} O^{n}(i)^{\frac{\sigma_{n}-1}{\sigma_{n}}}\right]^{\frac{\sigma_{n}}{\sigma_{n}-1}}
$$

where $\sigma_{n}$ is the elasticity of substitution between oil and labor and $b_{2}$ is a distribution 
parameter. Costs for the non-traded firm, denominated in dollars, is

$$
\phi^{n}=\frac{1}{A^{n}}\left[W^{1-\sigma_{n}}+b_{2}^{\sigma_{n}} P^{o 1-\sigma_{n}}\right]^{\frac{1}{1-\sigma_{n}}} .
$$

Note that as $\phi^{n}$ is costs denominated in dollars. Costs denominated in terms of the nontraded good are therefore given by $\frac{\phi^{n}}{P^{n}}$. The factor demands for $L^{n}(i)$ and $O^{n}(i)$ are respectively

$$
\begin{aligned}
& L^{n}(i)=\phi^{n \sigma_{n}} A^{n \sigma_{n}-1} W^{-\sigma_{n}} Q^{n}(i), \\
& O^{n}(i)=\phi^{n \sigma_{n}} A^{n \sigma_{n}-1} P^{o-\sigma_{n}} b_{2}^{\sigma_{n}} Q^{n}(i) .
\end{aligned}
$$

I assume that the differentiated goods are aggregated into a final non-traded good, $Q^{n}$, by a representative firm operating under perfect competition. This firm uses the technology

$$
Q^{n}=\left[\int_{0}^{1} Q^{n}(i)^{\frac{\theta^{n}-1}{\theta^{n}}}\right]^{\frac{\theta^{n}}{\theta^{n}-1}}
$$

where $\theta^{n}$ is the elasticity of substitution between the various goods. The zero profit condition for the representative firm implies that the demand for good $i$ is

$$
Q^{n}(i)=\left(\frac{\tilde{p}(i)}{\tilde{P}^{n}}\right)^{-\theta^{n}} Q^{n}
$$

and that the price index is

$$
\tilde{P}^{n}=\left[\int_{0}^{1} \tilde{p}(i)^{1-\theta^{n}} d i\right]^{\frac{1}{1-\theta^{n}}}
$$

Prices for the individual firms, $\tilde{p}(i)$, are sticky according to setup similar to Calvo (1983). Each firm $i$ resets its price when it receives a stochastic signal to do so. The signal follows a Poisson process with an average waiting time of $\frac{1}{\omega}$, so that $\omega$ can be calibrated to control the degree of price stickiness. I also assume that prices grow at rate equal to the steady state level of inflation. This ensures that the markup in steady state is only affected by the degree of substitutability between the goods, $\theta^{n}$, and not the steady state rate of inflation 
or other factors. Readers interested in more details or derivations regarding this are referred to Plante (2009b).

Given that a firm receives a signal to reset its price, the first order condition for $\tilde{p}(i)$ is found by solving the profit maximization problem,

$$
\max _{\tilde{p}(i)} \int_{t}^{\infty}\left\{\omega e^{-(s-t)(\rho+\omega)} \frac{\lambda_{1 s}}{\lambda_{1 t}}\left[\left(\frac{\tilde{p}(i)_{t} e^{\pi_{o}^{n}(s-t)}}{\tilde{P}_{s}^{n}}\right)^{1-\theta^{n}} Q_{s}^{n}-\frac{\phi_{s}^{n} Q_{s}^{n}}{P_{s}^{n}}\left(\frac{\tilde{p}(i)_{t} e^{\pi_{o}^{n}(s-t)}}{\tilde{P}_{s}^{n}}\right)^{-\theta^{n}}\right]\right\} d s
$$

The first order condition is

$$
\left(\theta^{n}-1\right) \int_{t}^{\infty} \omega e^{-(s-t)(\rho+\omega)} \frac{\lambda_{1 s}}{\lambda_{1 t}}\left(\frac{\tilde{p}(i) t e^{\pi_{o}^{n}(s-t)}}{\tilde{P}_{s}^{n}}\right)^{1-\theta^{n}} Q_{s}^{n}=\theta^{n} \int_{t}^{\infty} \omega e^{-(s-t)(\rho+\omega)} \frac{\lambda_{1 s}}{\lambda_{1 t}} \frac{\phi_{s}^{n} Q_{s}^{n}}{P_{s}^{n}}\left(\frac{\tilde{p}(i)_{t} e^{\pi_{o}^{n}(s-t)}}{\tilde{P}_{s}^{n}}\right)^{-\theta^{n}} d s
$$

I impose a symmetric equilibrium so that each firm that has the opportunity to choose its price chooses the same price, $\tilde{p}^{*}$. After imposing the symmetric equilibrium and performing a good deal of algebra, linearizing the first order condition around a steady state produces an equation that governs the evolution of $\pi^{n}$,

$$
\dot{\pi}^{n}=-\omega(\rho+\omega)\left(\frac{d \phi^{n}}{\phi_{o}^{n}}-\frac{d P^{n}}{P_{o}^{n}}\right)+\rho d \pi^{n} .
$$

This equation is just a continuous time analogue of the usual difference equation that occurs in discrete time models and holds for all values of $\pi_{o}^{n}$. Note that inflation in the non-traded sector is a function of costs denominated in terms of the non-traded good, $\frac{\phi^{n}}{P^{n}}$, not $\phi^{n}$. This occurs because from the point of view of the non-traded firms what matters is the price of non-traded good, not the price of the traded good.1 ${ }^{1}$

Aggregation is done linearly across firms. Equation (21) aggregated gives

$$
\int_{0}^{1} Q^{n}(i) d i=\Delta^{n} Q^{n}
$$

\footnotetext{
${ }^{1}$ The fact that I have chosen the traded good as the numeraire does not change the results. It only affects the way in which the variables are measured.
} 
where $\Delta^{n}$ is a state variable measuring price dispersion in the non-traded sector,

$$
\Delta^{n}=\int_{0}^{1}\left(\frac{\tilde{p}(i)}{\tilde{P}^{N}}\right)^{-\theta^{n}} d i
$$

Aggregation of equations (19) and 20 gives the aggregate demand for labor and oil,

$$
\begin{aligned}
L^{n} & =\phi^{n \sigma_{n}} A^{n \sigma_{n}-1} W^{-\sigma_{n}} Q^{n} \Delta^{n}, \\
O^{n} & =\phi^{n \sigma_{n}} A^{n \sigma_{n}-1} P^{o-\sigma_{n}} b_{2}^{\sigma_{n}} Q^{N} \Delta^{n} .
\end{aligned}
$$

It can be shown that the law of motion for $\Delta^{n}$ is

$$
\dot{\Delta}^{n}=\theta^{n} \Delta^{n}\left(\pi^{n}-\pi_{o}^{n}\right)+\omega p^{*-\theta^{n}}-\omega \Delta^{n}
$$

where $p^{*}=\frac{\tilde{p}^{*}}{\tilde{P}^{n}}$. A first order approximation of this equation gives

$$
\dot{\Delta}^{n}=-\omega d \Delta^{n}
$$

which shows that $\Delta^{n}$ is irrelevant for the paths of the variables to a first order.

\subsection{Gross Domestic Product}

The use of intermediate inputs means that GDP is not equal to the sum of gross output in the traded and non-traded sectors. I calculate real GDP, $Q^{g}$, as

$$
Q^{g}=Q^{t}+P^{n} Q^{n}-P^{o}\left(O^{t}+O^{n}\right)
$$

The GDP deflator, $\tilde{P}^{G D P}$ is calculated as the ratio of nominal GDP to real GDP, and GDP deflator inflation is $\pi^{G D P}=\frac{\dot{\tilde{P}}^{G D P}}{\tilde{P}^{G D P}}$. 


\subsection{The Public Sector}

The public sector consists of the central bank and the fiscal authorities, hereafter simply the government. The balance sheet of the central bank is

$$
M=M^{d}+e b_{g}^{*}
$$

where $M^{d}$ is the domestic component of the nominal money supply and $b_{g}^{*}$ is official holdings of the tradable bond. The growth of the money supply is given by

$$
\dot{M}=\dot{M}^{d}+e \dot{b}_{g}^{*}
$$

The consolidated government budget constraint is

$$
\dot{m}=T+\dot{b}_{g}^{*}-r^{*} b_{g}^{*}-\chi m
$$

For all cases considered here I assume that $T$ passively adjusts to clear the government budget constraint.

\subsection{Market Clearing in the Non-Traded Sector}

Total output must equal total spending on the non-traded consumption good. The market clearing condition in the non-tradable sector is therefore

$$
Q^{n}=C^{n}
$$

Note that output in the non-traded sector is demand determined so it adjusts to meet demand for the consumption good. 


\subsection{The Current Account}

In equilibrium $W L^{t}=Q^{t}-P^{o} O^{t}, \Pi^{n}=P^{n} Q^{n}-P^{o} O^{n}-W L^{n}$, and $b=0$. Using these equations in the agent's budget constraint, and then combining the resulting equation with the government budget constraint gives an equation linking the current account and net foreign asset accumulation,

$$
\dot{b}^{*}+\dot{b}_{g}^{*}=P^{n} Q^{n}+Q^{t}+r^{*}\left(b^{*}+b_{g}^{*}\right)-E-P^{o}\left(O^{t}+O^{n}\right)
$$

If one makes use of the market clearing condition for the non-tradables sector this reduces to

$$
\dot{b}^{*}+\dot{b}_{g}^{*}=Q^{t}+r^{*}\left(b^{*}+b_{g}^{*}\right)-C^{t}-P^{o}\left(O^{t}+O^{n}\right) .
$$

This equation simply states that the economy accumulates foreign assets whenever the sum of income from production of the traded good and foreign investment is greater than spending on traded goods.

\subsection{The Price of Oil}

I work under the assumption that shocks to the real price of oil are persistent, but temporary, in nature. Following a surprise shock the price returns monotonically to its steady state level according to

$$
\dot{P}^{o}=-\alpha\left(P^{o}-P_{o}^{o}\right), \alpha>0
$$

\subsection{Calibration}

The model is calibrated to an initial steady state. A table at the end of the text contains the starting values of the model's variables and the settings for the deep parameters. The following gives a brief discussion about the calibration choices for a few parameters which are important for the main results of the paper. The appendix contains a section explaining 
the procedure in more detail.

- Price Stickiness in the Non-traded Sector $(\omega)$ The average life of a price is $\frac{1}{\omega}$. The empirical evidence suggests a range between one to two quarters using disaggregated data but a longer life for more aggregated models. I choose a value of 2 so that on average prices are reset every half year.

- Elasticity of substitution between non-traded goods $\left(\theta^{n}\right)$ The value of $\theta^{n}$ controls the steady state markup of price over marginal cost in the non-traded sector. The calibrations for this parameter are all over the map so there is no one accepted calibration. I choose a value of 12 so that the markup is small but not negligible.

- Speed of Adjustment of Oil Prices $(\alpha)$ Estimates for this parameter exist for monthly and quarterly data. Pre 1986 data suggest a value between .95 and 1 for the corresponding AR(1) coefficient while post-86 data suggest a value around .80. This corresponds to a range for $\alpha$ between .20 and 0. I choose the conservative value of .10.

- Elasticity of substitution between oil and labor $\left(\sigma_{t}\right.$ and $\left.\sigma_{n}\right)$ Although empirical evidence for these elasticities for traded and non-traded sectors is non-existent, these parameters can be calibrated to match the price elasticity of oil demand for firms. A variety of studies using more aggregated data suggest that these elasticities are generally small, reflecting the difficulties of substituting for oil products in the short run. Given the sparsity of data, I set $\sigma_{t}=\sigma_{n}$ to keep the two sectors symmetric in this regard and use a value of .50 .

- Spending on oil by firms in the traded and non-traded sectors $\left(P_{o}^{o} O_{o}^{t}\right.$ and $P_{o}^{o} O_{o}^{n}$ Data on aggregate use of oil by all firms varies depending upon the price of oil, the time frame being considered, and the country in question. For the baseline calibration I work with $P_{o}^{o} O_{o}^{t}=P_{o}^{o} O_{o}^{n}=.03$. An alternative calibration where $P_{o}^{o} O_{o}^{n}=.02$ is also considered. As I explain later these two calibrations provide cover the two possible cases with regards to the ratio of the cost shares that was discussed in the introduction. 


\subsection{Solution Method}

I solve the model by deriving the core dynamic system of differential equations, the variables of which vary depending upon the policy considered. I then perform a first order linearization around the initial steady state and solve the differential equations using standard techniques. In all cases I check to ensure that a solution exists and that it is unique. The model is saddled with a unit root and to get around this when solving the model numerically I assume that $r^{*}$ is a function of the debt-GDP ratio of the economy,

$$
r^{*}=\rho+h\left(\frac{b^{*}+b_{g}^{*}}{P^{n} Q^{n}+Q^{t}-P^{o}\left(O^{t}+O^{n}\right)}-\frac{b_{o}^{*}+b_{g, o}^{*}}{P_{o}^{n} Q_{o}^{n}+Q_{o}^{t}-P_{o}^{o}\left(O_{o}^{t}+O_{o}^{n}\right)}\right), h<0 .
$$

This adds a small negative eigenvalue to the dynamic system instead of the 0 eigenvalue.

\section{Results}

Before considering specific policies I first derive some analytical results that hold regardless of the policy in place. Recall that the real unit cost functions for the traded and non-traded sectors are, respectively,

$$
\begin{aligned}
\phi^{t} & =\frac{1}{A^{t}}\left[W^{1-\sigma_{t}}+b_{1}^{\sigma_{t}} P^{o 1-\sigma_{t}}\right]^{\frac{1}{1-\sigma_{t}}} \\
\phi^{n} & =\frac{1}{A^{n}}\left[W^{1-\sigma_{n}}+b_{2}^{\sigma_{n}} P^{o 1-\sigma_{n}}\right]^{\frac{1}{1-\sigma_{n}}} .
\end{aligned}
$$

Costs in the traded sector are equal to unity and constant. By taking the total derivative of the equation for $\phi^{t}$ one can therefore solve for how $W$ changes as a function of the change in the real price of oil. Doing so gives

$$
\hat{W}=-\frac{\zeta_{o}^{t}}{\zeta_{l}^{t}} \hat{P}^{o}
$$

where $\zeta_{o}^{t}$ and $\zeta_{l}^{t}$ is the cost share of oil and labor, respectively, in the traded sector. Taking the total derivative of the equation for $\phi^{n}$ and using the result for the change in $W$ gives one 
the change in $\phi^{n}$,

$$
d \phi^{n}=\eta \hat{P}^{o}
$$

where

$$
\eta=\frac{P^{o} O^{n}}{Q^{n}}\left(1-\frac{\frac{\zeta_{o}^{t}}{\zeta_{l}^{t}}}{\frac{\zeta_{o}^{n}}{\zeta_{l}^{n}}}\right)
$$

and the terms $\zeta_{o}^{n}$ and $\zeta_{l}^{n}$ are just the cost shares for the non-traded sector.

Whether $\phi^{n}$ rises or falls depends upon the sign of $\eta$, which is determined entirely by whether or not the ratio of the cost share of oil to the cost share of labor is higher in the traded or non-traded sector. If the ratio is higher in the traded sector then $\eta$ is negative and $\phi^{n}$ falls when the price of oil rises. If the ratio is smaller in the traded sector then $\phi^{n}$ rises whenever the price of oil rises. The intuition behind this result is that when $\eta$ is negative the drop in $W$ is large enough to offset the increase in the price of oil so $\phi^{n}$ falls. In the case when $\eta$ is positive the drop in wages is not large enough to offset the rise in the price of oil and $\phi^{n}$ rises.

With these results in hand it is possible to begin thinking about the behavior of inflation in the non-traded sector because the linearized differential equation governing $\pi^{n}$ is a function of $d \phi^{n}-d P^{n}$. As $\tilde{P}^{n}$ is pre-determined at any point in time the initial change in $P^{n}$ will always be $\hat{P}^{n}=-\hat{e}$. It is through this mechanism that monetary policy can affect inflation in the non-traded sector. The reason this is true is that changes in the nominal exchange rate affect the domestic price of oil that the non-traded firms must pay vis-a-vis the price of the non-traded good. If the domestic currency appreciates (depreciates) then the cost of oil drops (rises) in terms of the price of the non-traded good. This does not matter for the firm in the traded sector because the price of the traded good varies directly with the nominal exchange rate. This will be the driving factor in many of the results that follow. 


\subsection{Stabilizing Non-Traded Inflation}

The first policy I consider is one where the central bank focuses on stabilizing the inflation rate of the non-traded good, $\pi^{n}$. To implement the policy I assume that the central bank publicly announces that it will adjust the nominal interest rate according to

$$
i=i_{o}+\alpha_{\pi}\left(\pi^{n}-\pi_{o}^{n}\right) .
$$

As the nominal interest rate is the monetary policy target, the nominal supply of money passively adjusts to clear the money market and the nominal exchange rate floats. The core dynamic system of the model under this policy consists of equations (1), (12), and (25) for

the jump variables $P^{n}, \lambda_{1}$, and $\pi^{n}$, and equations (33) and (34) for the state variables $b^{*}$ and $P^{o}$.

In the true model where $r=r^{*}$, or assuming that $d r$ is negligible and can be ignored, it is possible to derive some very useful analytical results for this policy. In particular, it is possible to show the conditions under which the policy produces a determinate solution and to also produce some results about the behavior of $\pi^{n}, P^{n}$, and several other variables on the transition path. This is possible because under this policy the system of linearized differential equations for $\pi^{n}, P^{n}$, and $P^{o}$ form a subsystem that can be solved independently of the other equations in the model.

The procedure for deriving the sub-system is as follows. The first order condition for $b$, equation (9), gives the interest rate parity condition. When linearized this equation shows us that

$$
d i=d \chi .
$$

Combining this with a linearized version of the monetary policy rule in equation (39) gives

$$
d \chi=\alpha_{\pi} d \pi^{n} .
$$

Making use of this result and the previously derived equation for $d \phi^{n}$ one can write the 
system of linearized equations for $P^{n}, \pi^{n}$, and $P^{o}$ as

$$
\left[\begin{array}{c}
\dot{P}^{n} \\
\dot{\pi}^{n} \\
\dot{P}^{o}
\end{array}\right]=\left[\begin{array}{ccc}
0 & P_{o}^{n}\left(1-\alpha_{\pi}\right) & 0 \\
k 1 & \rho & k 2 \\
0 & 0 & -\alpha
\end{array}\right]\left[\begin{array}{c}
d P^{n} \\
d \pi^{n} \\
d P^{o}
\end{array}\right]
$$

where

$$
\begin{aligned}
k 1 & =\frac{\omega(\rho+\omega)}{P_{o}^{n}}, \\
k 2 & =-\frac{\omega(\rho+\omega)}{\phi_{o}^{n}} \eta .
\end{aligned}
$$

The coefficient $k 1$ is always positive but $k 2$ may be greater than, equal to, or less than 0 depending upon whether or not $\eta$ is negative, zero, or positive.

The roots of the sub-system are

$$
\begin{aligned}
& r_{1}=-\alpha, \\
& r_{2}=\frac{1}{2}\left[\rho-\sqrt{4 \omega(\omega+\rho)\left(1-\alpha_{\pi}\right)+\rho^{2}}\right] \\
& r_{3}=\frac{1}{2}\left[\rho+\sqrt{4 \omega(\omega+\rho)\left(1-\alpha_{\pi}\right)+\rho^{2}}\right] .
\end{aligned}
$$

Under an inflation targeting policy both $\pi^{n}$ and $P^{n}$ are jump variables so if the system is to have a unique solution there must be 1 negative eigenvalue and 2 positive eigenvalues. The first root is always negative so it remains to show under what conditions the last two roots are positive. I presume first that the only relevant values of $\alpha_{\pi}$ are those greater than 0 . Under that condition we can see that $r_{2}<=>0$ as $\alpha_{\pi}<=>1$, with the possibility of an imaginary root if $\alpha_{\pi}$ is large enough. Given this we can rule out any value of $\alpha_{\pi} \leq 1$ as a possible candidate. For $r_{3}$, close inspection reveals that that root will always be greater than 0 for $\alpha_{\pi}>0$, with the possibility of an imaginary root for large enough values of $\alpha_{\pi}$. In other words, the condition under which this policy produces a unique solution is exactly the condition found in the standard closed economy New Keynesian model, namely $\alpha_{\pi}>1$. 
Making use of the eigenvector associated with $r_{1}$ the solution for the variables along the transition path is,

$$
\left[\begin{array}{l}
d P^{n} \\
d \pi^{n} \\
d P^{o}
\end{array}\right]=\left[\begin{array}{c}
\frac{-k 2\left(\alpha_{\pi}-1\right)}{\omega(\rho+\omega)\left(\alpha_{\pi}-1\right)+\alpha(\alpha+\rho)} \\
\frac{-k 2(\alpha)}{\omega(\rho+\omega)\left(\alpha_{\pi}-1\right)+\alpha(\alpha+\rho)} \\
1
\end{array}\right]\left[h_{1} e^{-\alpha t}\right],
$$

where $h 1$ is the initial surprise jump in the price of oil.

The solution for $\pi^{n}$ gives us two useful pieces of information. First, notice that for a given calibration that the deviations of $\pi^{n}$ from its target become smaller and smaller as $\alpha_{\pi}$ becomes larger and larger. This applies to both the initial jump and along the entire transition path. In other words, how much inflation varies on the transition path depends directly upon how strongly the central bank announces it will respond to a rise in inflation. Second, the direction of the initial jump in $\pi^{n}$ is entirely determined by the sign of $\eta$, operating through $k 2$. If $\eta$ is positive then $k 2$ is negative and non-traded inflation jumps up. If $\eta$ is negative then $k 2$ is positive and non-traded inflation jumps down.

The initial jump in the relative price depends upon both the solution just derived and the change in the relative price across steady states. For the simple model considered here, however, we can ignore the latter issue because the change across steady states is $0 .{ }^{2}$ As with $\pi^{n}$, the direction of the initial jump and the evolution of $P^{n}$ on the transition path is determined solely by the sign of $\eta$. For cases when $\eta$ is positive $P^{n}$ initially rises and then declines monotonically on the transition path. If $\eta$ is negative then $P^{n}$ falls initially and rises monotonically on the transition path. As $\tilde{P}^{n}$ is initially fixed, this means that the nominal exchange rate appreciates in the former case and depreciates in the latter case. The magnitude of the initial jump is also sensitive to the value of $\alpha_{\pi}$. In the limit as $\alpha_{\pi}$ goes to infinity the coefficient collapses to

$$
\frac{\theta^{n}}{\theta^{n}-1} \eta
$$

The intuition behind the results for $\pi^{n}$ and $P^{n}$ is simple. In order to keep $\pi^{n}$ close to its

\footnotetext{
${ }^{2}$ Since the shock is temporary wages do not change across the steady state and hence neither does $\phi^{n}$. Using the first order condition for $\tilde{p}(i)$ one can then show that $P^{n}$ does not change across steady state.
} 
target $\frac{\phi^{n}}{P^{n}}$ must remain nearly constant when the price of oil rises. As discussed earlier, the change in $W$ is pinned down in the traded sector and this then pins down the change in $\phi^{n}$, which may increase or decrease depending upon the sign of $\eta$. But the nominal exchange rate can adjust instantaneously to adjust $P^{n}$. For example, if $\eta$ is positive then wages do not fall enough to offset the rise in the price of oil so $\phi^{n}$ rises. In this case the nominal exchange rate must appreciate so as to reduce the cost of purchasing oil for the non-traded firms. The relative price of the non-traded good rises and this keeps $\frac{\phi^{n}}{P^{n}}$ nearly constant. The opposite results hold when the $\eta$ is negative. In this case the nominal exchange rate depreciates, which raises costs in the non-traded sector by just the right amount to keep non-traded inflation very close to its target.

Given the results for $\pi^{n}$ it is possible to derive results for some of the other variables, as well. The path of $\pi^{n}$ pins down the entire path of $\chi$ and $\pi^{C P I}$ as

$$
\begin{aligned}
d \chi & =\alpha_{\pi} d \pi^{n} \\
d \pi^{C P I} & =\left[\left(1-\gamma_{n}\right) \alpha_{\pi}+\gamma_{n}\right] d \pi^{n} .
\end{aligned}
$$

Under this policy both the rate of depreciation and CPI inflation vary directly with $\pi^{n}$ along the transition path.

It is also possible to link up the behavior of $\pi^{n}, i$, and what I will refer to as the non-traded real interest rate, $r^{n}$. To see where $r^{n}$ comes from, imagine that the agent had access to a bond indexed to $\tilde{P}^{n}$. This bond would have a real return of $r^{n}$ and the nominal interest rate on this bond would be

$$
i^{n}=r^{n}+\pi^{n}
$$

A no-arbitrage condition would ensure that $i^{n}=i$ along the transition path so

$$
r^{n}=r^{*}+\left(\chi-\pi^{n}\right) .
$$


A first order approximation of this equation gives

$$
d r^{n}=\left(\alpha_{\pi}-1\right) d \pi^{n}
$$

which shows that so long as $\alpha_{\pi}>1$ then the policy ensures that non-traded real rate rises whenever non-traded inflation rises above its steady state value. This is similar to the result that holds in closed economy New Keynesian models, except that in that in that case there is only one real interest rate. The no-arbitrage condition also implies that for cases where $\pi^{n}$ is kept close to its target that $i$ must be adjusted to vary with $r^{n}$. Importantly, the exact manner in which $i$ must be adjusted depends upon $\eta$ and so it is not always true that interest rates need to be raised to stabilize $\pi^{n}$.

All of the results derived so far technically only hold for the model where $r=r *$ while the solution method used is just an approximation to the true model. It remains to be shown that numerical results are in line with results just derived. To show that this is so, I solve the model numerically and plot the impulse responses for a number of variables. All plots show the percentage deviations of the variables from their steady state values, with the exception of the inflation and interest rates, which are in percentages, and the trade and current account deficits, which are in units of GDP. The plot for aggregate consumption expenditure, $E$, incorporates relative price changes while $E(f i x)$ does not. The variables $T B, C A$, and $O S$ are the trade balance, the current account balance, and total spending on oil by firms.

Figure 1 shows the impulse responses when there is a 20 percent rise in the price of oil, with $\alpha_{\pi}$ calibrated to a large value. Although the solution is an approximation all of the results match those from the analytical solutions previously derived. The rise in the real price of oil causes wages to fall but under the baseline calibration $\eta$ is positive so the drop in wages is not big enough to offset the rise in the price of oil in the non-traded sector and $\phi^{n}$ rises. Stabilizing $\pi^{n}$ therefore requires the currency to instantaneously appreciate which causes the relative price of the non-traded good to initially jump up. With $\pi^{n}$ stabilized close to its target, variations in $P^{n}$ are due almost entirely to variations in $\chi$, which is above 
its steady state level along the entire transition path. The nominal interest rate and $r^{n}$ both rise initially and then fall over time.

The behavior of the real variables basically follows what we would expect from economic intuition. The rise in the price of oil reduces the demand for oil in both sectors and brings about a reduction in the amount of output produced in the traded sector. Income is lower for the agent so aggregate consumption expenditure drops, and this income effect along with the relative price movement induces a sharp and substantial drop in output in the non-traded sector. Real money balances decline because of the slightly higher interest rates and the reduction in aggregate consumption. The economy makes use of its ability to smooth the shock out by borrowing significantly from international capital markets.

Figure 2 makes explicit the importance of the sign of $\eta$ by showing the impulse responses under the alternative calibration where $P_{o}^{o} O_{o}^{n}$ is set to 0.02 instead of 0.03 . This alternative

calibration makes $\eta$ negative instead of positive so $\phi^{n}$ falls and $\frac{\phi^{n}}{P^{n}}$ is kept constant only if there is an offsetting depreciation of the currency. Under the same exact specification of monetary policy, it is now the case that $P^{n}, \chi, r^{n}$, and $i$ initially fall and then rise over time. As the relative price of the non-traded good is temporarily lower than that of the traded good, output and consumption of this good decline less than what occurs under the case where $\eta$ is positive.

\subsection{Stabilizing CPI Inflation}

In practice central banks focus on stabilizing an inflation variable other than $\pi^{n}$, generally CPI inflation, so it is worthwhile considering the implications of this type of policy. I assume that the central bank implements this policy by adjusting the nominal rate according to the rule

$$
i=i_{o}+\alpha_{\pi}\left(\pi^{C P I}-\pi_{o}^{C P I}\right)
$$

which is exactly the same as the rule found in equation 39 except that $\pi^{n}$ is replaced with $\pi^{C P I}$. 
As with the policy of stabilizing $\pi^{n}$ it is possible to derive analytical results about the conditions under which this policy delivers a unique solution and analytical results about the behavior of some of the variables along the transition path. This is true because under this policy it is again possible to derive a sub-system in $P^{n}, \pi^{n}$, and $P^{o}$ separate from the other equations of the model.

The procedure for deriving the sub-system is basically the same as before. The linearized versions of the monetary policy rule, the equation for CPI inflation, and the interest-parity condition can be combined to give an equation for $\chi$ of the form

$$
d \chi=\frac{\alpha_{\pi} \gamma_{n}}{1-\alpha_{\pi}\left(1-\gamma_{n}\right)} d \pi^{n}
$$

As before, use this equation in the linearized equation for $P^{n}$. Once this is done one again has a set of linearized differential equations for $P^{n}, \pi^{n}$ and $P^{o}$ that are functions of these three variables alone.

There are two jump variables in the subsystem so there must be two positive roots if there is to be a unique solution. The main result here is that this policy can produce multiple equilibria in the economy for a wide range of calibrations for $\alpha_{\pi}$. The roots of the subsystem in this case are

$$
\begin{aligned}
& r_{1}=-\alpha \\
& r_{2}=\frac{1}{2}\left(\rho-\sqrt{\frac{4 \omega(\omega+\rho)\left(1-\alpha_{\pi}\right)}{1-\alpha_{\pi}\left(1-\gamma_{n}\right)}+\rho^{2}}\right) \\
& r_{3}=\frac{1}{2}\left(\rho+\sqrt{\frac{4 \omega(\omega+\rho)\left(1-\alpha_{\pi}\right)}{1-\alpha_{\pi}\left(1-\gamma_{n}\right)}+\rho^{2}}\right) .
\end{aligned}
$$

From the equation for $r_{2}$ we can immediately see that there will be trouble depending upon the value of $\alpha_{\pi}\left(1-\gamma_{n}\right)$. For cases where $\alpha_{\pi}<\frac{1}{1-\gamma_{n}}, r_{2}$ will be positive with the possibility of a complex root. If $\alpha_{\pi}>\frac{1}{1-\gamma_{n}}$ then $r_{2}$ will be negative and there will be multiple equilibria. This can be seen by noting that the first term in the square root will be positive in this case and since we are adding a positive number to $\rho^{2}$ we are guaranteed a negative root. Under 
the borderline case where $\alpha_{\pi}=\frac{1}{1-\gamma_{n}}, r_{2}$ explodes to complex negative infinity and we also have indeterminacy.

It is possible to give a clear explanation of why this occurs by looking at the behavior of $\chi, i$, and $r^{n}$. The solution for $\chi$ shows that in cases where the policy produces an indeterminate solution $\chi$ varies inversely with $\pi^{n}$. Substituting the equation for $\chi$ into the equation for CPI inflation gives

$$
d \pi^{C P I}=\frac{\gamma_{n}}{1-\alpha_{\pi}\left(1-\gamma_{n}\right)} d \pi^{n}
$$

which shows that the change in $\chi$ is enough to force CPI inflation to also vary inversely with $\pi^{n}$. Substituting the equation for $d \pi^{C P I}$ into the linearized monetary policy rule one has

$$
d i=\frac{\alpha_{\pi} \gamma_{n}}{1-\alpha_{\pi}\left(1-\gamma_{n}\right)} d \pi^{n}
$$

and using this in the equation for $r^{n}$ one gets

$$
d r^{n}=\frac{\alpha_{\pi}-1}{1-\alpha_{\pi}\left(1-\gamma_{n}\right)}
$$

From these two equations we can see that a rise in $\pi^{n}$ leads to a fall in both $i$ and $r^{n}$. But if the intuition carries over from other models the drop in $r^{n}$ spurs further increases in $\pi^{n}$ which, through the policy rule, spurs further decreases in $\chi, i$, and $r^{n}$. When $\alpha_{\pi}\left(1-\gamma_{n}\right)$ is greater than 1 the policy creates a response that allows self-fulfilling expectations to drive the economy. Note that when $\alpha_{\pi}\left(1-\gamma_{n}\right)$ is less then 1 then these self-fulfilling expectations can not occur because a rise in $\pi^{n}$ brings about a rise in $r^{n}$ and this prevents inflation from spiralling out of control.

In cases where there is a unique solution, the solutions of the three variables on the transition path are

$$
\left[\begin{array}{l}
d P^{n} \\
d \pi^{n} \\
d P^{o}
\end{array}\right]=\left[\begin{array}{c}
-\frac{k 2}{k 1}\left[1+\frac{\alpha+\rho}{\frac{\omega(\rho+\omega)\left(1-\alpha_{\pi}\right)}{1-\alpha_{\pi}\left(1-\gamma_{n}\right)}-\alpha(\alpha+\rho)}\right] \\
\frac{\alpha(\rho+\omega)\left(1-\alpha_{\pi}\right)}{1-\alpha_{\pi}\left(1-\gamma_{n}\right)}-\alpha(\alpha+\rho) \\
1
\end{array}\right]\left[h_{1} e^{-\alpha t}\right],
$$


where $h 1$ is again the initial surprise jump in the price of oil. So long as $\alpha_{\pi}\left(1-\gamma_{n}\right)<1$, the direction of the initial jump in inflation is determined by the sign of $\eta$ and the magnitude is a decreasing function of $\alpha_{\pi}\left(1-\gamma_{n}\right)$. In particular, in the limit as $\alpha_{\pi}\left(1-\gamma_{n}\right)$ approaches 1 the initial jump approaches 0 . Since this can only occur if there is a very specific response from the nominal exchange rate this implies that for this calibration the policy will behave very closely to the one where the central bank fully stabilizes $\pi^{n}$.

The equations are, unfortunately, too complicated to be able to derive any more analytical results so I now turn to numerical simulations. I avoid the indeterminacy problem by calibrating $\alpha_{\pi}$ to 1.99 , which is near the indeterminacy boundary for calibration used here. This also implies that the monetary authority stabilizes CPI inflation to the greatest extent possible.

The impulse response functions for the baseline calibration are shown in figure 3 . Because a calibration of $\alpha_{\pi}=1.99$ is successful at stabilizing $\pi^{n}$ close to its target level the results are very similar to the ones found in figure 1. Given the similarities of the results for these two policies I refer the reader to the previous section for a discussion about them. For brevity's sake, I do not display the response functions for the alternative calibration, since these will mirror closely the results found in figure 2 .

\subsection{A Crawling Peg}

While the number of economies that completely fix their exchange rates are few, many countries still occasionally intervene in foreign exchange markets. This section provides results for the polar case where the nominal exchange rate is completely fixed, as opposed to the inflation targeting schemes where the nominal exchange rate was completely free to float. Under a crawling peg $\chi$ is the monetary policy variable, the nominal exchange rate is pre-determined at any point in time, and real money balances adjusts through the capital account. I assume for simplicity that $\chi$ is set equal to its steady state level $\chi_{o}$. In order to defend the peg the central bank intervenes in the foreign exchange market whenever 
necessary using its stock of foreign exchange reserves $b_{g}^{*}$. The core dynamic system of the model under this policy consists of equations (12) and (25) for the jump variables $\lambda_{1}$ and $\pi^{n}$, and equations (1), (33), and (34) for the state variables $P^{n}, k$, and $P^{o}$, where $k=b^{*}+b_{g}^{*}$.

As with the inflation targeting policies it is possible to derive analytically the conditions under which this policy produces a unique solution and also some analytical results for several variables when $r=r^{*}$. Under this policy the system of equations for $P^{n}, \pi^{n}$, and $P^{o}$ can be written as

$$
\left[\begin{array}{c}
\dot{P}^{n} \\
\dot{\pi}^{n} \\
\dot{P}^{o}
\end{array}\right]=\left[\begin{array}{ccc}
0 & P_{o}^{n} & 0 \\
k 1 & \rho & k 2 \\
0 & 0 & -\alpha
\end{array}\right]\left[\begin{array}{c}
d P^{n} \\
d \pi^{n} \\
d P^{o}
\end{array}\right]
$$

where $k 1$ and $k 2$ are the same as before. The three eigenvalues are

$$
\begin{aligned}
& r_{1}=-\alpha \\
& r_{2}=\frac{1}{2}\left(\rho-\sqrt{4 \omega(\omega+\rho)+\rho^{2}}\right) \\
& r_{3}=\frac{1}{2}\left(\rho+\sqrt{4 \omega(\omega+\rho)+\rho^{2}}\right) .
\end{aligned}
$$

In this case $P^{n}$ is a state variables so a unique solution requires two negative eigenvalues. It is obvious that both $r_{1}$ and $r_{2}$ will always be negative for realistic calibrations of $\omega$ so this policy always generates a unique solution in the subsystem. Interestingly enough, this policy produces a unique solution even though $r^{n}$ falls when inflation rises because the policy does not create a feedback effect that leads to self-fulfilling expectations.

After solving for the eigenvectors one can show that along the transition path

$$
\left[\begin{array}{l}
d P^{n} \\
d \pi^{n} \\
d P^{o}
\end{array}\right]=\left[\begin{array}{cc}
-\frac{k 2 P_{o}^{n}}{\omega(\rho+\omega)-\alpha(\alpha+\rho)} & -\frac{\rho+\sqrt{4 \rho(\rho+\omega)+\rho^{2}}}{2 k 1} \\
\frac{\alpha k 2}{\omega(\rho+\omega)-\alpha(\alpha+\rho)} & 1 \\
1 & 0
\end{array}\right]\left[\begin{array}{c}
h_{1} e^{-\alpha t} \\
h_{2} e^{r_{2} t}
\end{array}\right],
$$


where $h 1$ is again just the initial jump in oil prices and

$$
h 2=-\frac{2 \omega(\rho+\omega) k 2}{[\omega(\rho+\omega)-\alpha(\alpha+\rho)]\left[\rho+\sqrt{4 \omega(\rho+\omega)+\rho^{2}}\right]} h 1 .
$$

Note that the sign of $h 2$ is determined entirely by the sign of $\eta$ through the term $k 2$.

These solutions are more complicated than in the previous cases and do not lead to many easily interpretable solutions. But after performing some algebra it can be shown that the initial jump in non-traded inflation is

$$
\left[\alpha-\frac{2 \omega(\rho+\omega)}{\rho+\sqrt{4 \omega(\rho+\omega)+\rho^{2}}}\right] \frac{k 2}{\omega(\omega+\rho)-\alpha(\alpha+\rho)} h 1 .
$$

While it is not possible to sign the initial jump for all possible values of the deep parameters, so long as $\omega$ is greater than $\alpha$, a likely case, the jump in inflation is pinned down by the sign of $\eta$, with inflation rising immediately if $\eta$ is positive and falling if $\eta$ is negative. With the nominal exchange rate fixed variations in $\phi^{n}$ are not immediately offset by movements in $P^{n}$. Therefore costs rise or fall, depending upon the sign of $\eta$, and firms offset this by raising or lowering their prices, which leads to non-traded inflation rising or falling.

Several other solutions are available. With $\chi$ and $r^{*}$ fixed $d i=0$ at all times. Therefore

$$
d r^{n}=-d \pi^{n}
$$

Under a fixed exchange rate policy the non-traded real interest consequently falls whenever non-traded inflation rises. Also, the change in CPI inflation is simply

$$
d \pi^{C P I}=\gamma_{n} \pi^{n}
$$

so CPI inflation varies directly with non-traded inflation.

As before, more comprehensive results can only be had by solving the model numerically. The impulse response functions for the baseline calibration are shown in figure 4 . The rise in 
the price of oil raises $\phi^{n}$ but since $e$ is fixed this brings about an immediate rise in non-traded inflation. Over time firms adjust to the temporarily high cost of oil by raising their prices, which causes the relative price of the non-traded good to rise over time. The fact that $P^{n}$ is temporarily lower than what occurs under the inflation targeting policy manifests itself in a higher level of $Q^{n}$, initially. As $P^{n}$ rises, however, the agent reduces consumption of the non-traded good, which shows up as a rapid decline in $Q^{n}$ over the first year. Figure 5 shows the results for the alternative calibration of the model. When $\eta$ is negative the rise in oil prices now reduces $\phi^{n}$ which in turn causes $\pi^{n}$ to drop initially and for $P^{n}$ to fall over time, while $r^{n}$ initially rises.

\section{Conclusions}

The contribution of this paper is to examine monetary policy responses to oil price shocks in a small, open economy with traded and non-traded goods as opposed to the large, closed economy model that has been the mainstay so far. This change allows one to consider issues with exchange rates and relative prices that are necessarily ignored in the closed economy models.

The main result in this paper is that because of the asymmetric effects a rise in the price of oil has on costs in the traded and non-traded sectors it is possible for the same specification of monetary policy to produce very different behavior in inflation, the nominal exchange rate, and the relative price of the non-traded good depending upon the cost shares of oil and labor in the two sectors. Under the assumptions made in the paper the behavior of wages is pinned down in the traded goods sector. If the ratio of the cost share of oil to the cost share

of labor is higher (lower) in the traded sector then costs and inflation in the non-traded sector fall (rise) unless monetary policy responds appropriately. A successful inflation targeter who stabilizes $\pi^{n}$ does so by offsetting these changes in cost by bringing about exactly the correct movement needed in the nominal exchange rate. The exact movement depends, though, on ratios and hence it is possible for this policy to cause a nominal exchange rate depreciation 
or appreciation. A similar result holds for an inflation targeter who stabilizes CPI inflation, for certain calibrations of the policy rule. For similar reasons, a policy of fixed nominal exchange rates, because it precludes any such adjustment in the nominal exchange rate, can bring about increases or decreases in non-traded inflation.

The second set of important results is related to the ability of the policies to produce unique solutions. I have also shown analytically under what conditions the three policies produce multiple equilibria in the economy. A policy that stabilizes non-traded inflation only produces an indeterminate solution if the nominal interest rate is not raised more than one-for-one with a rise in non-traded inflation. A policy that stabilizes CPI inflation, however, produces multiple equilibria for a wide range of calibrations. The analytical results show that whether this occurs or not is a function of how strongly the central bank pledges to respond to rises in CPI inflation and the share of the non-traded good in the CPI. If the pledged response is too strong then the policy response leads to self-fulfilling expectations. A crawling peg, unlike the other two policies, always produces a unique solution for the model considered here.

While this paper has produced a number of useful and interesting results, the model used is simple and highly stylized and future research could expand upon the model in several ways. One useful line of work would be to introduce further frictions in the model, such as sticky nominal wages or less then full labor mobility between the two sectors. A second line of work would be to add a second country and make endogenous the foreign variables of the model. While this would be a significantly more complicated model it would allow for greater realism and a much wider range of questions that could be investigated than with the simple model used here. 
Table 1: Calibrated Parameters and Steady State Values

$\begin{array}{lc}\text { Parameter } & \text { Value } \\ \tau & .50 \\ \sigma_{c} & .50 \\ \rho & .05 \\ \omega & 2 \\ \alpha & .10 \\ \sigma_{t} & .50 \\ \sigma_{n} & .50 \\ \mu & 1 \\ m_{o} & .08 \\ P_{o}^{n} & 1 \\ C_{o}^{n} & .50 \\ C_{o}^{t} & .50 \\ P^{o} O^{t} & .03 \\ P^{o} O^{n} & .03\end{array}$


Figure 1: Non-Traded Inflation, Baseline Calibration
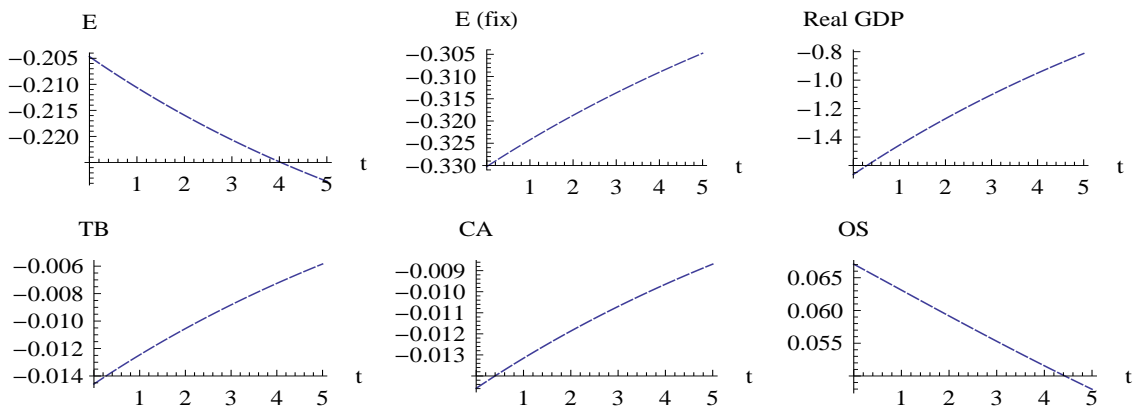

CA

OS
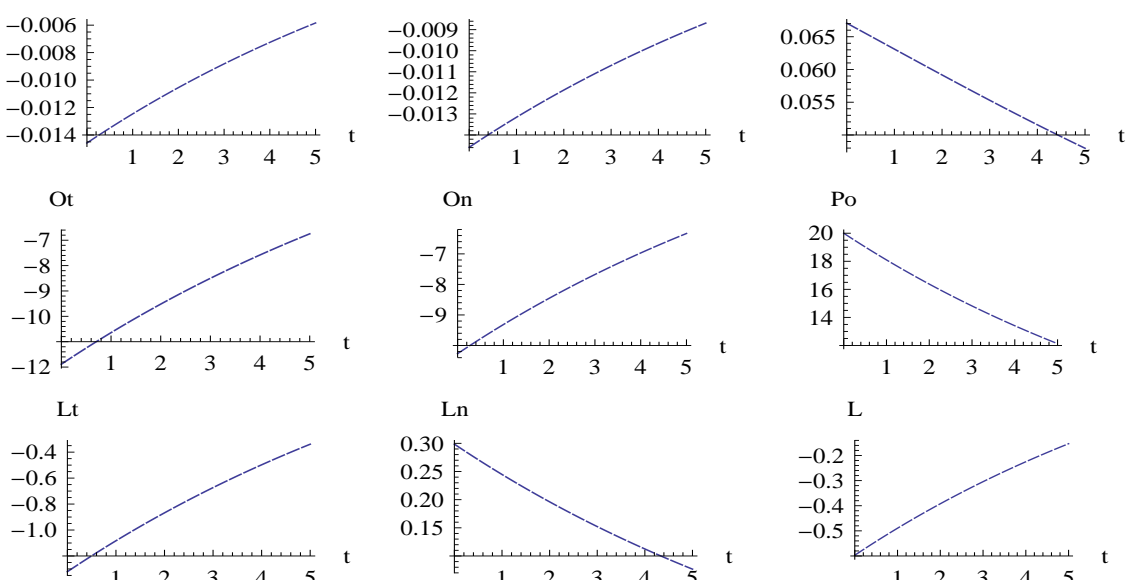

L

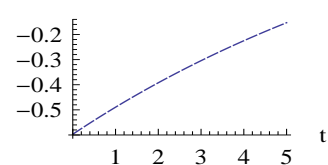

Qt

Qn
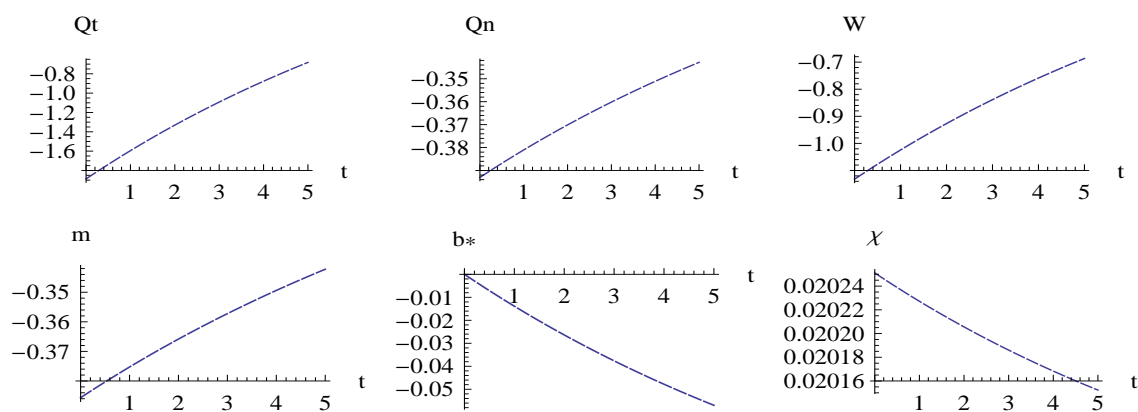

$\mathrm{b} *$

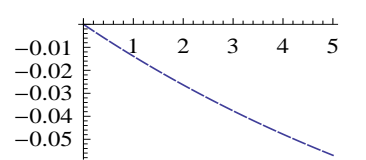

x
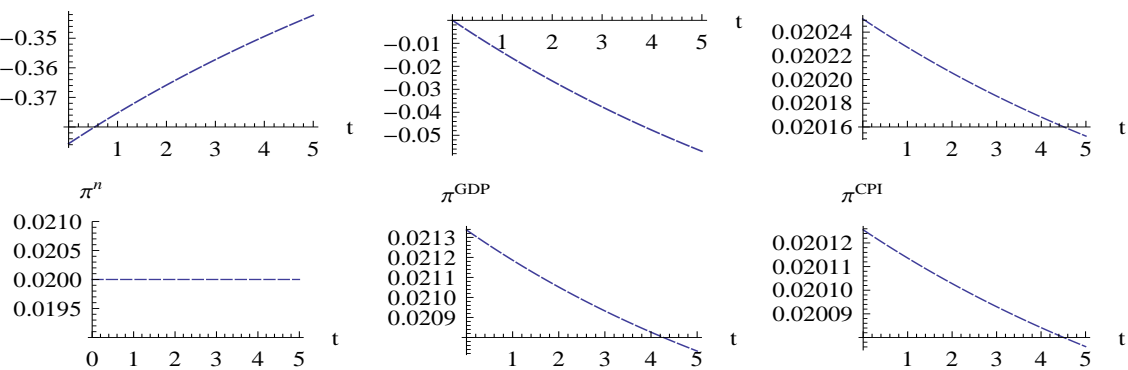

$\pi^{\mathrm{GDP}}$

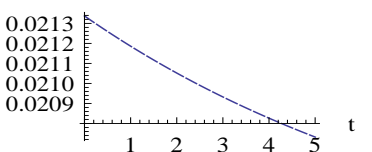

$\pi^{\mathrm{CPI}}$

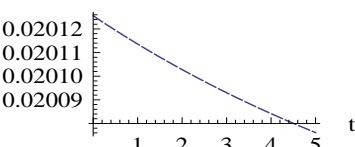

r
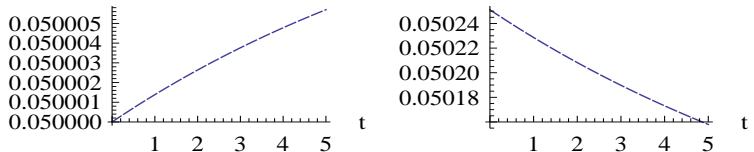

i

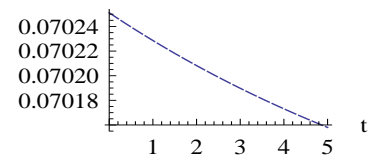

Pn

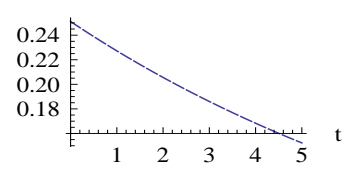


Figure 2: Non-Traded Inflation, Alternative Calibration
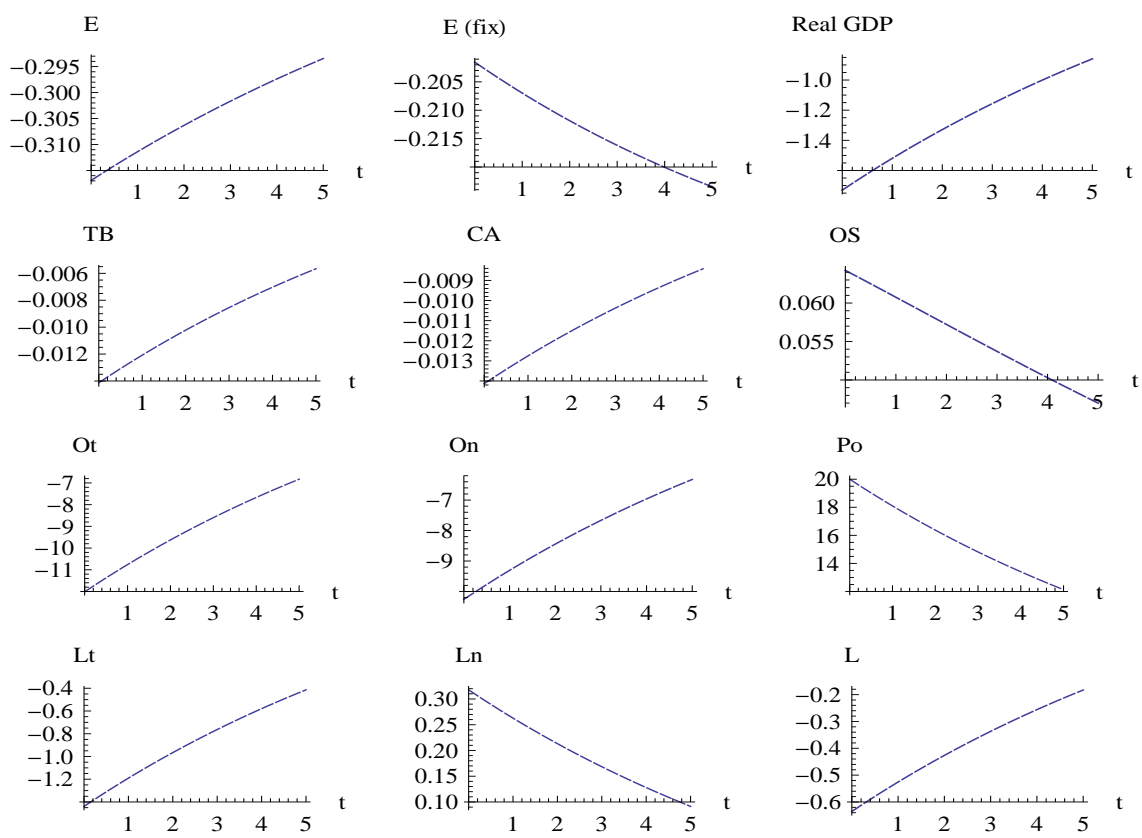

L
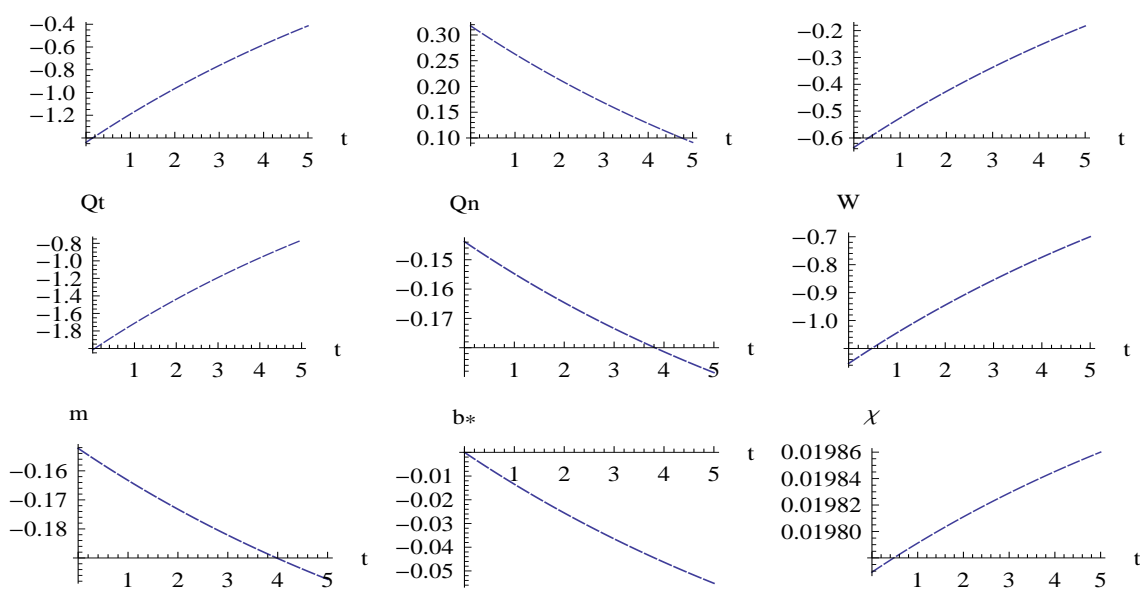

$\mathrm{b} *$
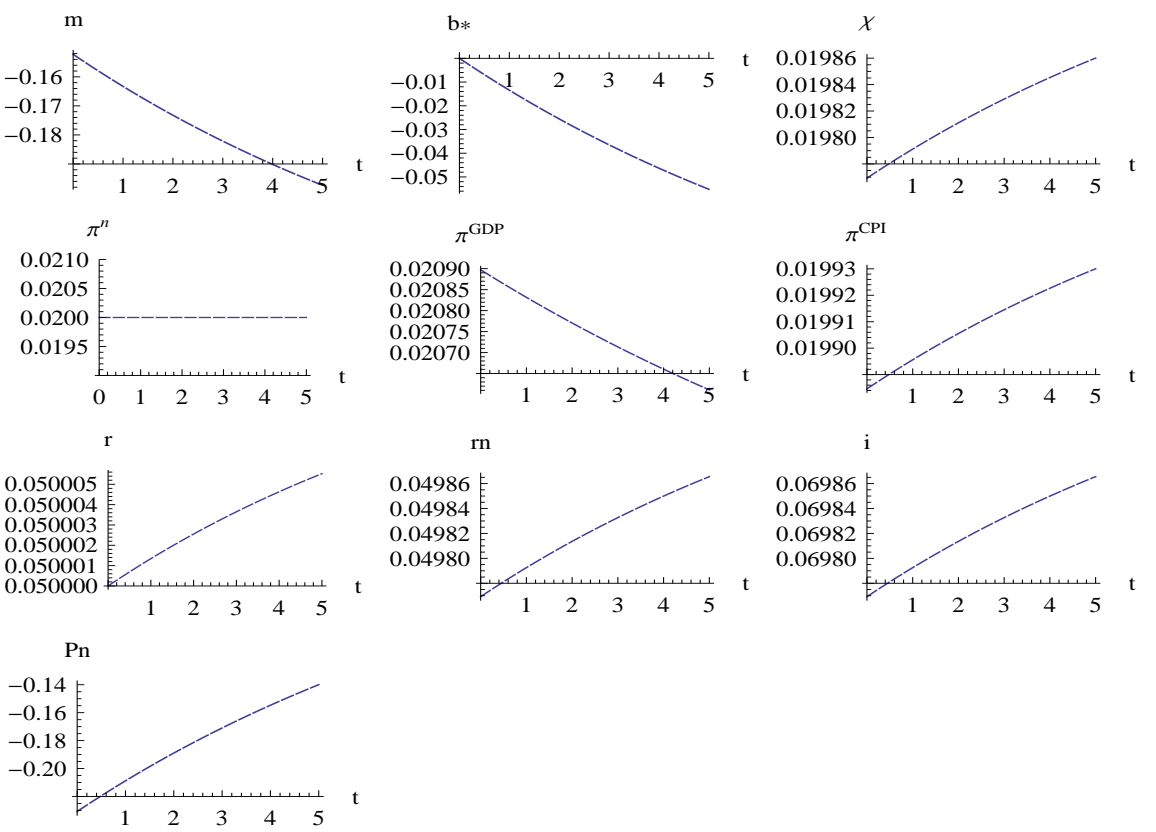
Figure 3: CPI Inflation, Baseline Calibration
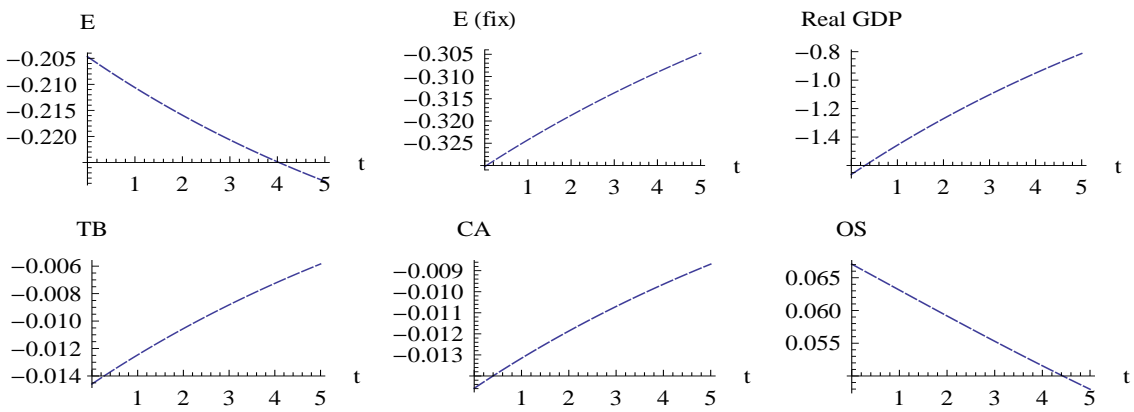

CA

OS
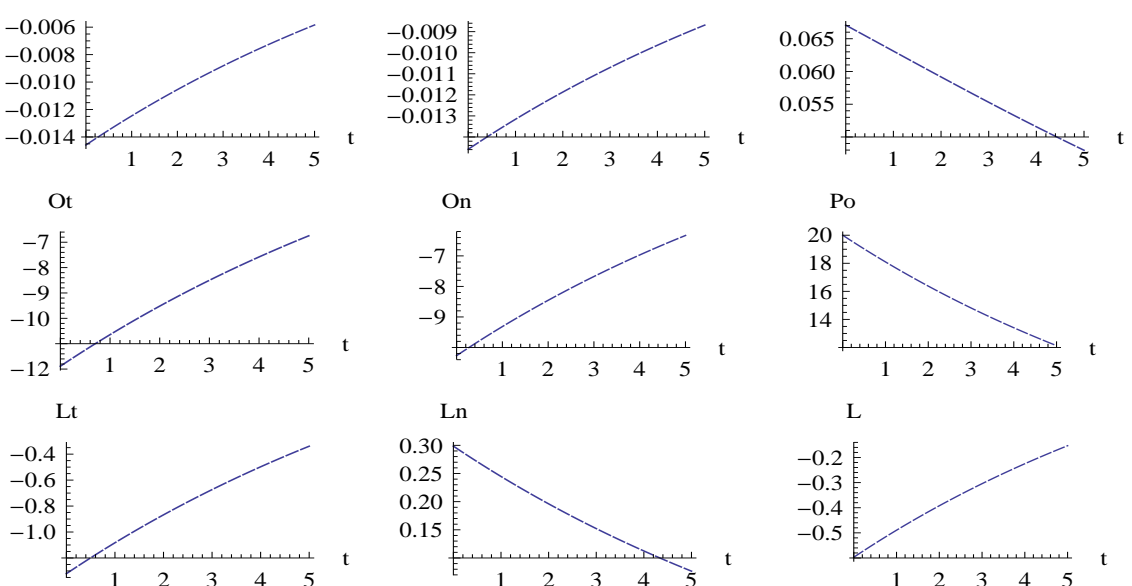

L

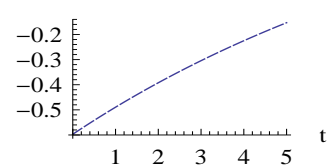

Qt

Qn
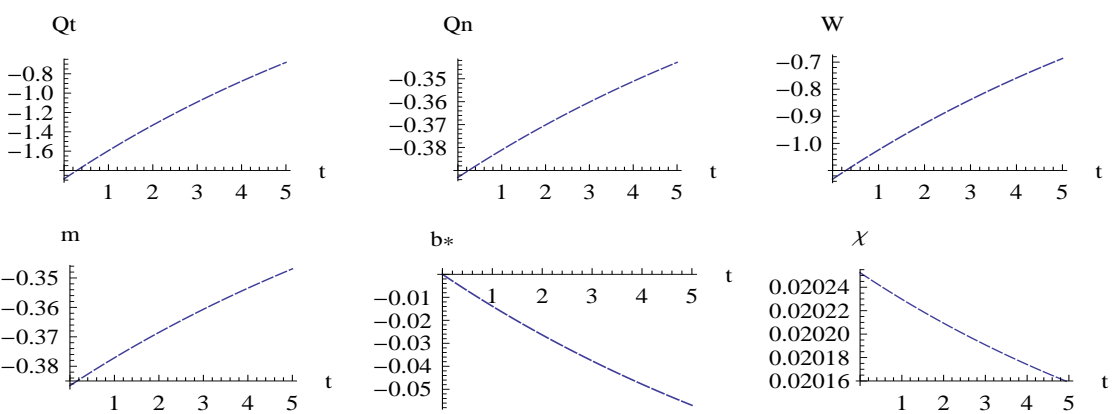

$\mathrm{b} *$
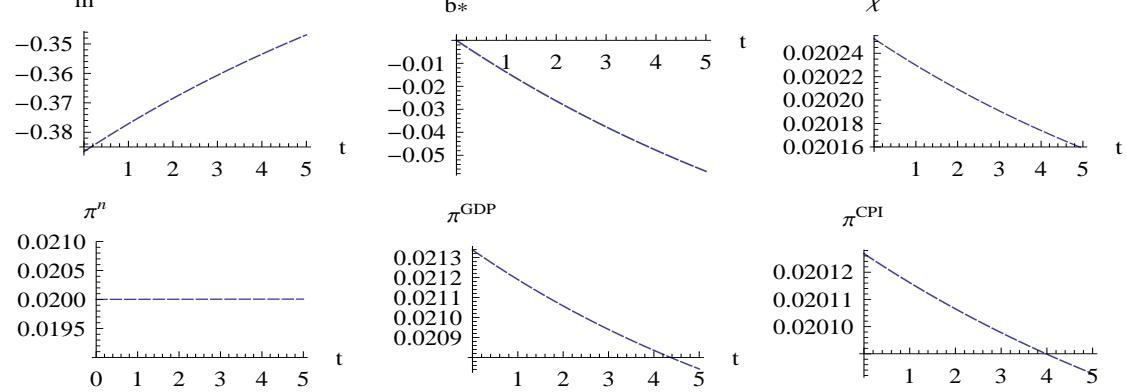

$\pi^{\mathrm{GDP}}$

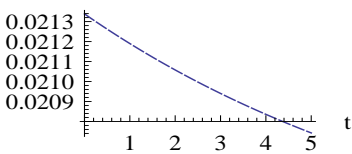

$\pi^{\mathrm{CPI}}$

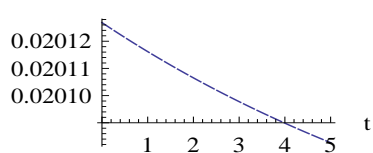

r
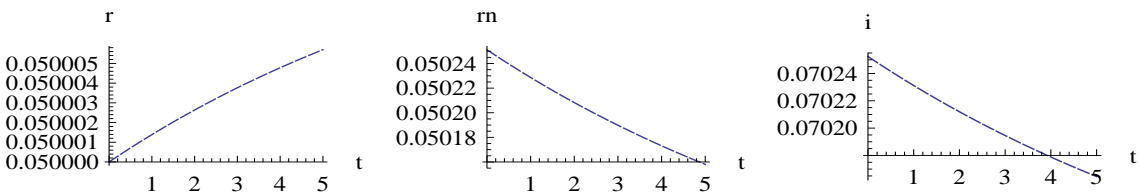

Pn

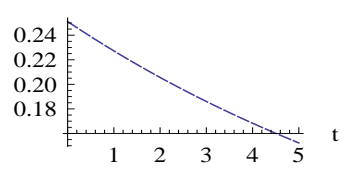




\section{Figure 4: Fixed Rates, Baseline Calibration}
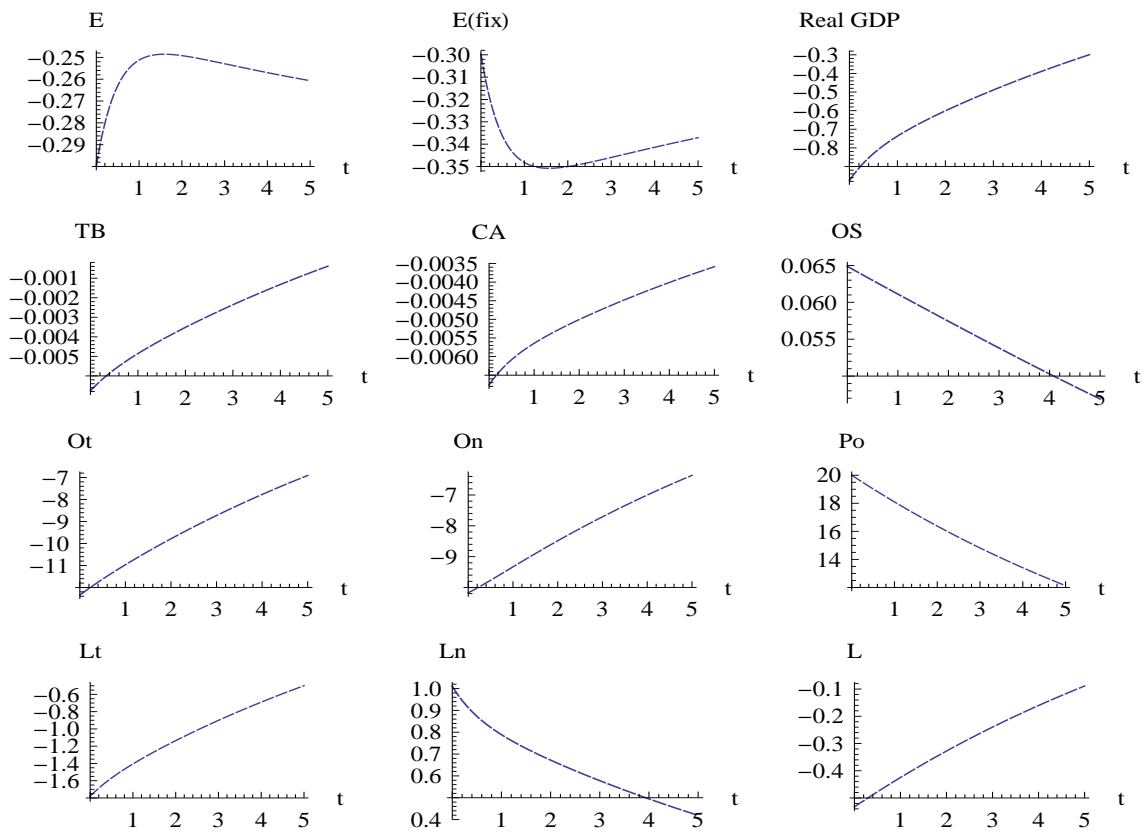

Qt
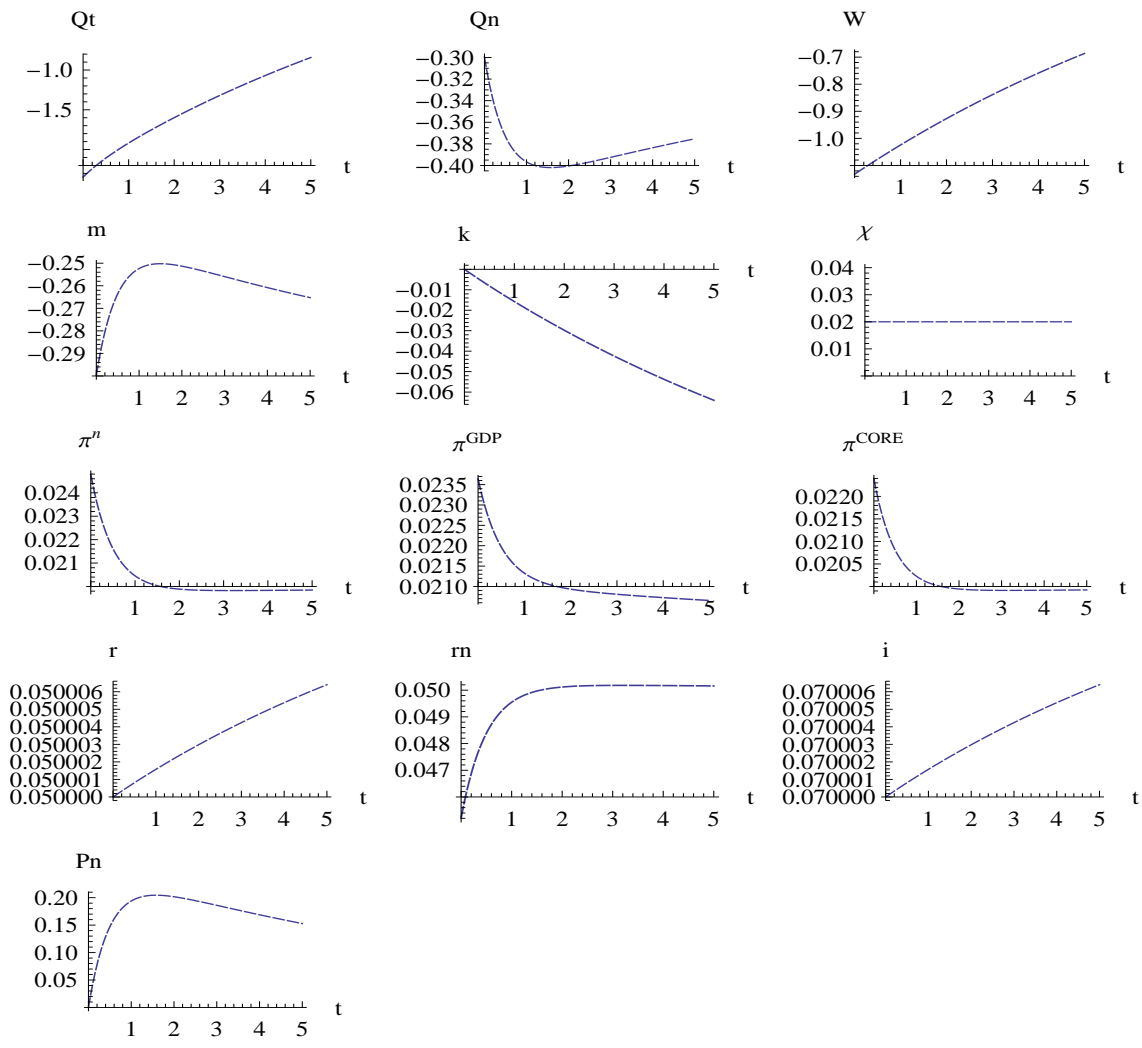


\section{Figure 5: Fixed Rates, Alternative Calibration}
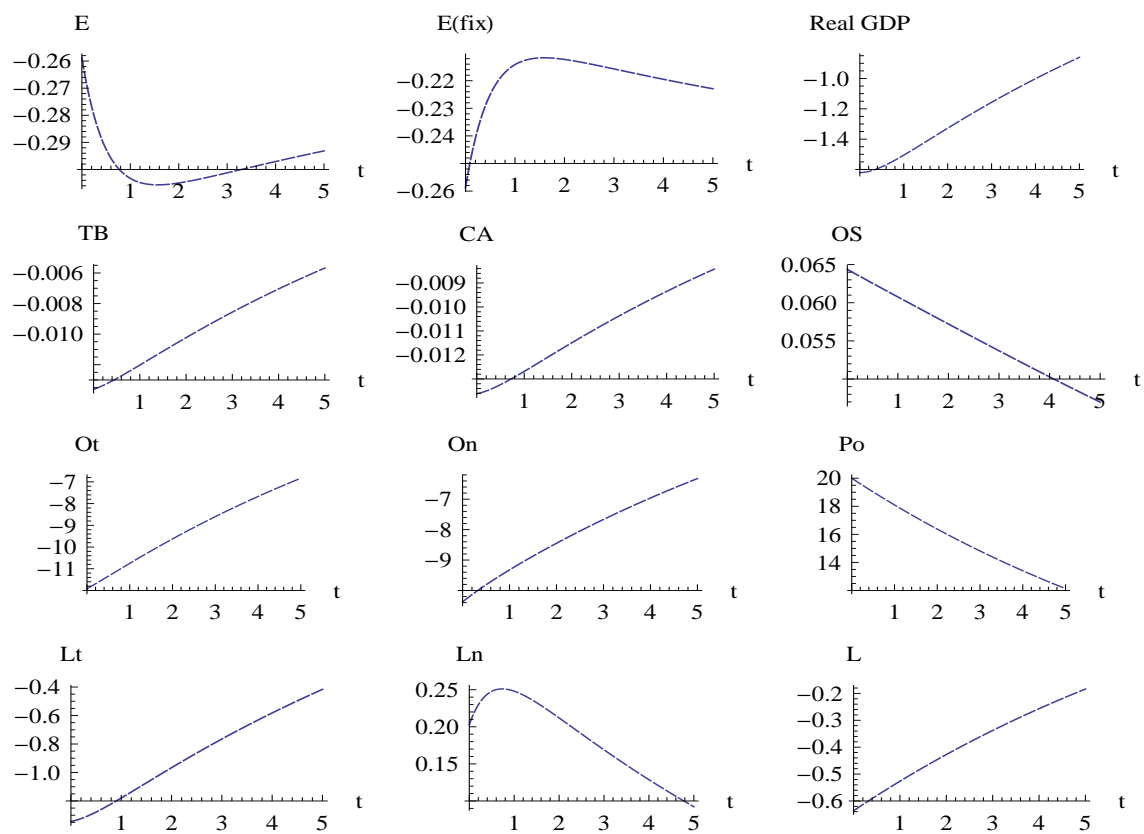

L
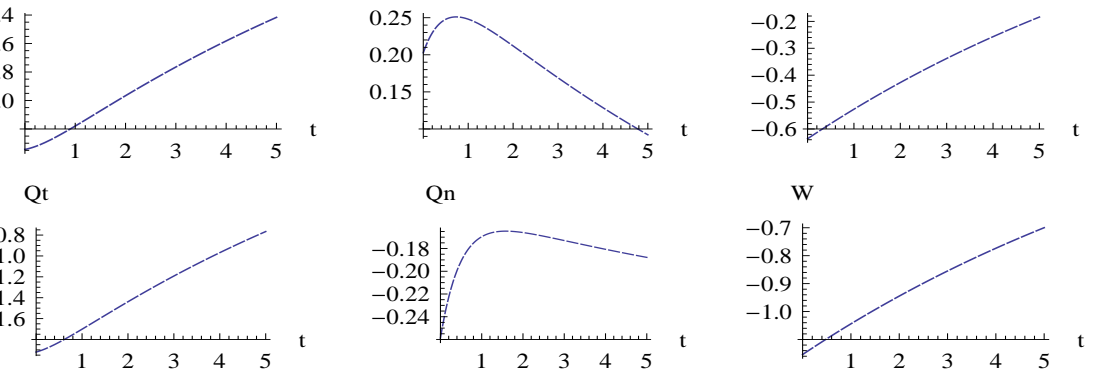

W
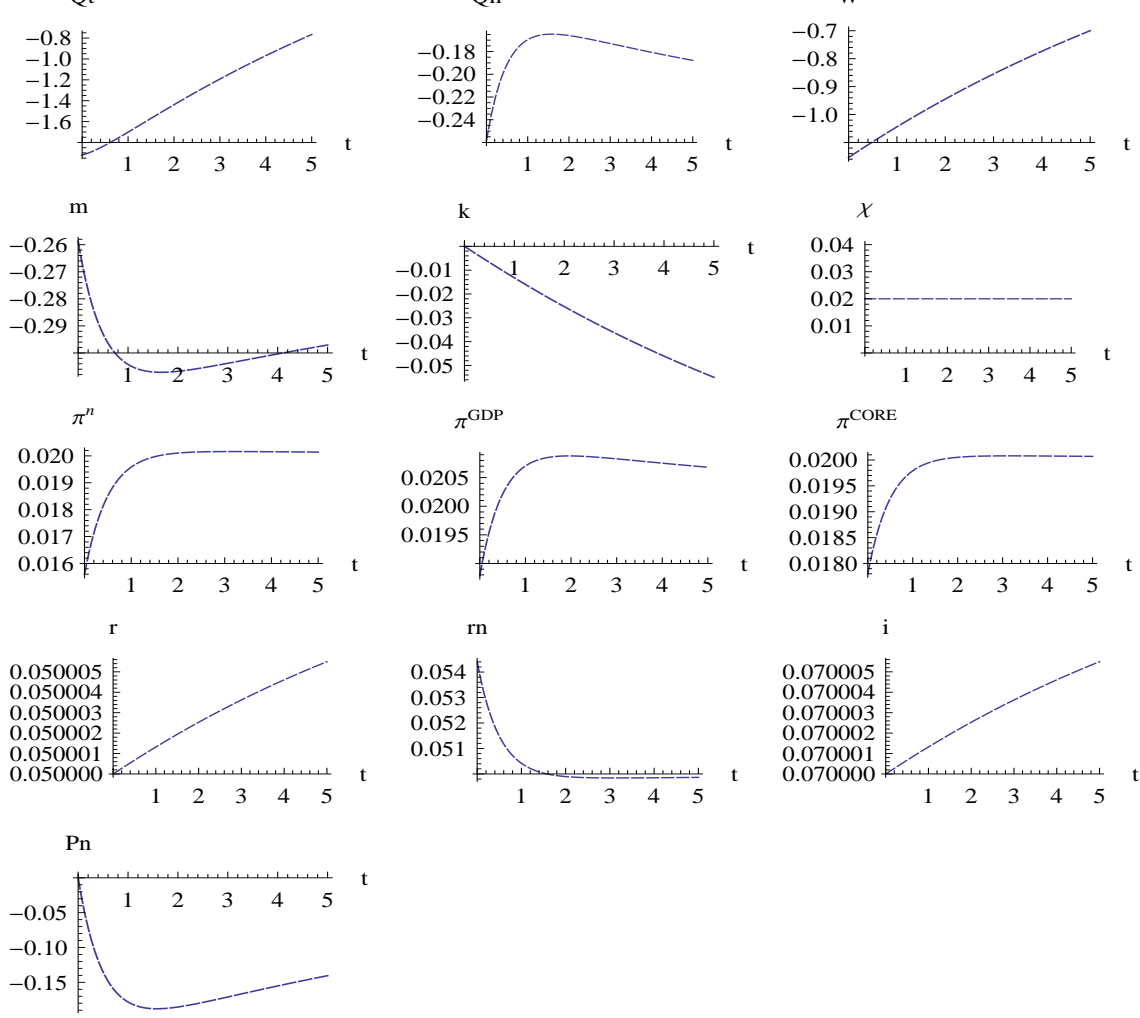


\section{References}

Bodenstein, M., C. Erceg, and L. Guerrieri (2008): "Optimal Monetary Policy with Distinct Core and Headline Inflation Rates," Journal of Monetary Economics, forthcoming.

Calvo, G. A. (1983): "Staggered Prices in a Utility-Maximizing Framework," Journal of Monetary Economics, 12, 383-398.

Dhawan, R., And K. Jeske (2007): "Taylor Rules with Headline Inflation: A Bad Idea!," Working Paper.

Leduc, S., And K. Sill (2004): "A Quantitative Analysis of Oil-Price Shocks, Systematic Monetary Policy, and Economic Downturns," Journal of Monetary Economics, 51, 781808.

Plante, M. (2009a): "How Should Monetary Policy Respond to Changes in the Relative Price of Oil?," Working Paper.

(2009b): "Two Calvo Pricing Models for Continuous Time, Open Economy Models with Traded and Non-Traded Goods," Notes. 